\title{
Analysis of the Main Sources of Errors in GPS Measurements for ensuring the movement of Ships
}

\author{
Iryna Smyrnova ${ }^{1}$, Alona Leshchenko ${ }^{2}$, Dmytro Makarchuk ${ }^{3}$, Oleg Nesterov ${ }^{4}$ Olena Bezlutska, ${ }^{5}$, Mariia Chumachenko ${ }^{6}$ \\ ${ }^{1}$ Deputy Director for Scientific and Pedagogical Work, Danube Institute of the National University "Odesa Maritime Academy", Ukraine, \\ phd.smyrnova@gmail.com, scopus667@gmail.com \\ ${ }^{2}$ Department of Humanities, Kherson State Maritime Academy, Ukraine, \\ scopus667@gmail.com \\ ${ }^{3}$ Department of Navigation, Kherson State Maritime Academy, Ukraine, \\ scopus667@gmail.com \\ ${ }^{4}$ Department of «Navigation and Ship Management», Azov Maritime Institute Odessa Maritime Academy National University, Ukraine, \\ nesterovoleg1@gmail.com \\ ${ }^{5}$ Department of Humanities, Kherson State Maritime Academy Kherson, Ukraine, \\ bezlutskaya@ukr.net \\ ${ }^{6}$ Department of General Sciences, Danube Institute of the National University “Odesa Maritime Academy”,Ukraine, \\ scopus667@gmail.com
}

\begin{abstract}
The article analyzes the capabilities of navigation systems. The accuracy of measurements by the absolute method is considered, where the dependence on a number of sources of errors is indicated.

It has been determined that the main performance characteristics are related to the accuracy of determining the coordinates of the receiver. With the current state of the art technology, improved performance is expected in the areas of satellite life, data processing techniques and information transfer methods.
\end{abstract}

Key words: Navigation Systems, Errors, GPS, GLONASS, Positioning.

\section{INTRODUCTION}

Satellite radio navigation systems were originally developed for military purposes - the location of various mobile objects. But with the improvement of this system and methods of working with it, the scope of its application also grew: from the navigation of civil (not related to military departments) ships to the compilation of high-precision geodetic maps.

At the moment, the technology of positioning using satellite navigation systems has been so simplified that it has become possible to use it as an anti-theft device by private car owners.

The system is able to provide globality, accuracy, continuity, high availability and a number of other requirements. Accurate determination of coordinates and time is the most urgent task for a wide range of scientific and technical applications. These are higher geodesy, geodynamics, cartography, geodetic and aerial photography, air navigation, navigation of sea and river vessels, navigation of land transport and other areas. By the end of the last century, two such systems were created. These are the American Global Positioning System (GPS) - the Global Positioning System (or positioning) and the Russian GLOBAL Navigation Satellite System (GLONASS). The main task of such systems is to determine coordinates and time. In addition to their direct purpose, these systems are used to solve scientific problems. This is due to the appearance over the past 10 years of an international network of GPS receivers, which numbers more than 1000 pieces. Thanks to this, it became possible to study geodynamic processes on a global scale.

To solve these and many other problems, various types of receivers are used, but, no matter how different the spheres of GPS application, they all have one thing in common - the need for accurate determination of coordinates. It can be noted that the errors that lead to inaccuracies in determining the position when solving different problems are, for the most part, the same. But the methods used to fix them are often very different. This is mainly due to the fact that we have different requirements for accuracy and conditions under which positioning occurs, and the quality and level of the receiver also play an important role.

The capabilities of navigation systems will expand due to modernization, but for modernization it is necessary to outline the goals of improvement, that is, to analyze the operation of these systems and the factors affecting their operation. This shows the relevance of my work, as it is devoted to the analysis of the operational characteristics of satellite navigation systems and the influence on their operation of various factors.

The purpose of the article is to analyze the operational characteristics, as well as a number of sources of errors in satellite navigation systems GPS / GLONASS. 
Iryna Smyrnova et al., International Journal of Emerging Trends in Engineering Research, 8(9), September 2020, $5593-5597$

\section{MAIN MATERIAL}

The measurement accuracy of the absolute method depends on a number of sources of error. These sources include:

- inaccuracies in the forecast of ephemeris and the departure of the time scales of the constellation of satellites, which are formed during calculations and bookmarking from control stations to satellites;

- orbital disturbances and time scale drifts caused by gravitational and other effects;

- signal delays in the ionosphere caused by the presence of an inhomogeneous ionization density in the vertical distribution; - signal delays in the troposphere caused by changes in temperature, pressure and humidity in the surface layer of the atmosphere;

- GPS receiver noise caused by electromagnetic interference at the receiver input;

- multipath (multipath) signal propagation caused by signal reception from reflecting surfaces.

The error valuesalso depend on the type of code (P- or C / A-), that is, the code with which the pseudo-range is determined. The components of the positioning errors of the absolute method for GPS are given in Table 1.

Table 1: Values of errors of the absolute method

\begin{tabular}{|c|c|c|}
\hline $\begin{array}{c}\text { Sources and types } \\
\text { errors }\end{array}$ & $\begin{array}{c}\text { Using P- code, } \\
\mathrm{m}\end{array}$ & $\begin{array}{c}\text { Using C/A- code, } \\
\mathrm{m}\end{array}$ \\
\hline $\begin{array}{c}\text { Ephemeris forecast } \\
\text { inaccuracy }\end{array}$ & 2,00 & 2,00 \\
\hline Receiver noise & 0,20 & 1,50 \\
\hline $\begin{array}{c}\text { Signal delay in the } \\
\text { ionosphere }\end{array}$ & 2,30 & 3,50 \\
\hline $\begin{array}{c}\text { Signal delay in the } \\
\text { troposphere }\end{array}$ & 0,40 & 0,40 \\
\hline $\begin{array}{c}\text { Orbital disturbance } \\
\text { and unmodulated } \\
\text { timescale drifts }\end{array}$ & 3,00 & 3,00 \\
\hline $\begin{array}{c}\text { Multipath } \\
\text { propagation }\end{array}$ & 1,20 & 1,20 \\
\hline Other sources & 0,15 & 0,60 \\
\hline $\begin{array}{c}\text { Equivalent to RMS } \\
\text { range measurement } \\
\text { errors }\end{array}$ & 4,50 & 5,40 \\
\hline
\end{tabular}

Positioning errors depend not only on errors in determining the navigation parameter, but also on the location of satellites and consumers in space. Satellite Geometry, represents the geometric locations of the satellites. The more satellites are scattered in the sky, the better the satellite geometry, and vice versa. Figure 1 gives a graphical explanation of the dependence of accuracy on satellite geometry[1-7].

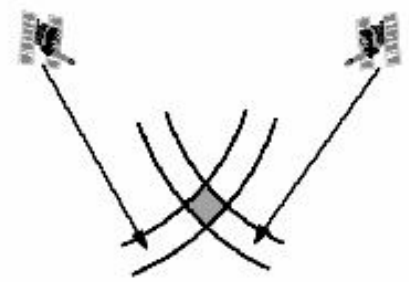

Figure 1: Good satellite geometry

If we are using only two satellites (two-dimensional case), then in this case, the receiver will be located at the intersection of two circles; each has a radius equal to the distance between the satellite and the receiver. Because, due to measurement errors, the satellite-to-receiver distance will not be accurate and therefore there will be a region of uncertainty. By combining measurements from these two satellites, it can be seen that the receiver will be located within the uncertainty region (shaded area in Figures 1 and 2). The smaller the region of uncertainty, the more accurately the position of the receiver will be calculated, respectively, if two satellites are located far from each other, then the size of the region of uncertainty will be small. Conversely, if the satellites are close to each other, the uncertainty area is large, as shown in Fig. 2.

The effect of satellite geometry can be characterized by a dimensionless quantity - the dilution of precision (DOP) factor. DOP values calculated based on satellite geometry relative to receiver.

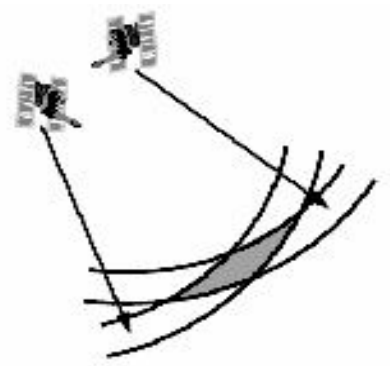

Figure 2. Poor satellite geometry

In practice, various forms of DOP are used, depending on the needs of the users. For example, in conventional positioning, the user may be interested in knowing the effect of satellite geometry in determining a three-dimensional position (latitude, longitude, and altitude). This is possible by examining the value of the position dilution of precision (PDOP). In other words, PDOP represents the contribution of satellite geometry in determining $3 \mathrm{D}$ position.

The time factor of degradation of accuracy (TDOP) is also used, which describes the degree of influence of the error of the clock readings on the accuracy of determining the coordinates.

For an integral assessment of the choice of a particular constellation of spacecraft (satellites), the geometric factor GDOP (Geometrie Dilution Of Precision) is used, which is the combined effect of PDOP and TDOP. 
Iryna Smyrnova et al., International Journal of Emerging Trends in Engineering Research, 8(9), September 2020, $5593-5597$

In practical navigation measurements, the maximum allowable geometric factor is less than seven (GDOP <7), the optimal GDOP value is approximately $3[1-3,10,14,20-22]$.

\section{Differential method errors}

The use of the differential method can significantly reduce the influence of some sources of errors. In fact, the systematic components of the errors (for inaccurate prediction of ephemeris, orbital disturbances, and unmodulated drifts of the time scale) are excluded, and the random components of the errors are reduced compared to the standard method.

Table 2: Values of errors of the differential method

\begin{tabular}{|c|c|c|}
\hline $\begin{array}{c}\text { Sources and types } \\
\text { errors }\end{array}$ & $\begin{array}{c}\text { Using P- code, } \\
\mathrm{m}\end{array}$ & $\begin{array}{c}\text { Using C/A- } \\
\text { code, } \mathrm{m}\end{array}$ \\
\hline $\begin{array}{c}\text { Signal delay in the } \\
\text { ionosphere }\end{array}$ & 0,10 & 0,10 \\
\hline $\begin{array}{c}\text { Signal delay in the } \\
\text { troposphere }\end{array}$ & 0,10 & 0,10 \\
\hline Receiver noise & 0,25 & 1,50 \\
\hline Multipath propagation & 1,20 & 1,20 \\
\hline Other sources & 0,15 & 0,60 \\
\hline $\begin{array}{c}\text { Equivalent to RMS } \\
\text { range measurement } \\
\text { errors }\end{array}$ & 2,00 & 1,20 \\
\hline
\end{tabular}

\section{Phase Differential Method Errors}

Measurement errors due to various factors can be estimated within the following limits.

The instrumental error in measuring the phase differences is determined within $1 \%$ phase cycle, i.e., is $3,6^{\circ}$.

Taking into account the above parameter values, the noise component of the phase difference has the value $0,26^{\circ}$.

The error due to the mismatch of the phase factors of electromagnetic waves arriving at the receiver antenna (antenna phase inhomogeneity) is, according to different sources, $\pm 2 \mathrm{~mm}$. The relative error in determining the speed of light in vacuum matters $410^{-9}$.

The refractive index of the atmosphere during the propagation of GPS / GLONASS electromagnetic waves depends mainly on the parameters of the ionosphere and troposphere. The influence of the troposphere during phase measurements is estimated by the relative error $0,210^{-6}$.

The influence of the ionosphere is reduced with phase measurements at two carrier frequencies. The relative error for the influence of the ionosphere is brought to the value $110^{-8}$.

In the receiving equipment, the reference oscillators are designed according to the scheme with quartz frequency stabilization $[10,11,13-18]$. The frequency shaping error is $=1$ $10^{-6}$.
Taking into account the above errors, without taking into account the effect of multipath, the accuracy of linear measurements is determined by the ratio

$$
M_{D}=3 m m+1 \cdot 10^{-6} \mathrm{D} .
$$

Multipath error in receivers should be considered as an appropriate contribution to the phase or pseudorange measurements from the reflected signals.

Multipath is difficult to characterize as a whole, since its amplitude and phase depend on many parameters, although some of them are fairly constant. This makes it possible to observe the multipath, repeating daily, in accordance with the frequency of the orbits of the satellite radio navigation system.

In general, any object near the receiver antenna whose surface is smooth for radio waves of 19 or $24 \mathrm{sm}$ will act as a multipath source. These are buildings, trees, and the surface of the Earth.

In extreme cases, the receiver may temporarily acquire the reflected signal, and this may account for a single loop break that occurs in certain circumstances with some receivers.

Radio waves entering the receiver antenna from the navigation satellite are divided into two types: direct waves entering the receiver antenna directly from the navigation satellite, and reflected waves from the earth's surface and surrounding objects.

The electric field of the direct wave from the satellite is determined by the ratio:

$$
\mathrm{E}_{\mathrm{p}}=\mathrm{E}_{\mathrm{o}} \times \cos (\omega \mathrm{t}+\varphi),
$$

In general, the reflected signal will be the sum of the signals reflected from the surrounding objects and the earth's surface, which allows them to be written in the following form:

$$
\mathrm{E}_{\mathrm{R}}=\mathrm{E}_{\mathrm{RO}}+\mathrm{E}_{\mathrm{RG}} \text {, }
$$

The reflected waves are the sum of a number of waves $n$ reflected from various objects and points on the earth's surface surrounding the antenna.

Since these waves have the same frequencies, but different amplitudes and phases, the resulting field of reflected waves with a low reflection coefficient

$K=0,1-0,4$ (this coefficient characterizes the degree of attenuation of the signal during reflection). It is known that the sum of harmonic signals with the same frequencies and different amplitudes and phases gives the resulting harmonic signal. The sum of the direct and reflected waves in the receiver antenna will give the resulting field, which can be represented as a vector sum:

$$
\mathrm{E}=\mathrm{E}_{\mathrm{P}}+\mathrm{E}_{\mathrm{R}}=\mathrm{E}_{\mathrm{S}} \times \cos (\omega \mathrm{t}+\varphi+\delta \varphi),
$$


Iryna Smyrnova et al., International Journal of Emerging Trends in Engineering Research, 8(9), September 2020, 5593 - 5597

The angle between the vectors is:

$$
\Delta \varphi=\varphi-\langle\varphi\rangle
$$

Since the reflection of radio waves occurs from points randomly distributed in space, and the value is evenly distributed in the range from 0 to 2 , therefore, the phase difference between the vectors and obeys the same distribution.

The maximum distortion corresponds to the phase difference values equal to 90 and $270^{\circ}$, and the minimum distortions will be at values equal to 0 and $180^{\circ}$.

Thus, if you change the path difference between the direct and reflected waves within the wavelength and perform measurements, the error, due to the multipath, will change according to a law close to sinusoidal. The average of the results obtained will be largely free from the effects of multipath.

The effect of multipath is effectively averaged over long time intervals. For short periods of time (up to 20-30 minutes, depending on antenna height and rate of change in elevation angle), multipath does not average to zero, and this can seriously affect the results of kinematic and rapid-static surveys, where the observation time does not exceed a few minutes. In such cases, errors of tens of millimeters can occur. The effect of multipath can be up to $10 \mathrm{sm}$. Difficulties in ensuring an accurate relationship of the phase center to the geometric center does not allow it to be a true universal millimeter measuring instrument even at short distances, despite the high resolution of carrier wave phase measurements.

To reduce phase changes and phase center problems, manufacturers generally recommend the use of the same type of antennas aligned in the same direction. Some of the antenna errors are application specific, for example, kinematics in the air (on an airplane) with a reference receiver on Earth.

The same phase response is very desirable here, i.e. spherical radiation pattern. It conflicts with the need to make the antenna "blind" for low altitudes in order to reduce its sensitivity to multipath signals.

\section{CONCLUSION}

Thus, the main performance characteristics are related to the accuracy of determining the coordinates of the receiver. With the current state of the art technology, improved performance is expected in the areas of satellite life, data processing techniques and information transfer methods.

In connection with the plans for the modernization of the GPS system, we will mention what the main possibilities it will open up to increase accuracy. Two new additional coded civil signals ( $\mathrm{C} / \mathrm{A}$ code on L2 and a new signal on L5) will enhance the user experience in high-precision measurement applications on long and short baselines, such as aircraft precision approach and automatic landing, mapping, geodetic and geophysical measurements, since the time of ambiguity resolution will decrease and the length of baselines will increase, which will allow using the best ionospheric correction at long distances. These actions will improve the accuracy of autonomous positioning. For scientific and geodetic measurements that do not use real-time, the centimeter level of accuracy will be achieved faster and at lower cost than now. This will be possible by using three frequencies to facilitate the disambiguation process when performing highly accurate phase measurements. It also reduces the chances of any accidental interference with the GPS system.

\section{REFERENCES}

1 K. Oduan, B. Guinot. Time measurement of GPS base. Moscow: Technosphere, 2002.

2 Lipkin I.A. Satellite navigation systems. Moscow: 2006.

3 E.L. Afraimovich. GPS-monitoring of the Earth's upper atmosphere. Irkutsk: GU NTs RBKh VSNTs SO RAMS, 2006, 479 p.

4 A. V. Koshelev, A. K. Sinyakin. Physical principles of GPS / GLONASS operation. Monograph, Novosibirsk: $S G G A, 2009$, pp.110.

5 A.A. Gennicke, G.G. Pobedinsky. Global satellite positioning systems and their application in geodesy. M., 2004.

6 A.V. Koshelev. To the determination of the refractive index of the atmosphere for high-precision geodetic measurements. Novosibirsk: SGGA, 2010, pp. 23.

$7 \mathrm{Yu}$. A. Golikov. Calculation of the main technical and economic indicators of the work of a small enterprise. Novosibirsk, SSGA, 2004, pp. 17.

8 O.Skoblikov and V. Knyazyev. Properties of Conductive Shells Exposed to Electromagnetic Impulse of Lightning, International Conference on Lightning Protection (ICLP'2012), Vienna, Austrian, 2012, pp. 1-8.

9 H. Khudov, S. Glukhov, O. Maistrenko, A. Fedorov, A. Andriienko, O. Koplik, The Method of ADS-B Receiver Systems Synchronization Using MLAT Technologies in the Course of Radar Control of Air Environment, International Journal of Emerging Trends in Engineering Research, Vol. 8. № 5, 2020, pp. 1946-1951. doi:10.30534/ijeter/2020/78852020.10.

10 H. Khudov, O. Makoveychuk, I. Khizhnyak, I. Yuzova , A. Irkha, and V. Khudov. The Mosaic Sustainable Marker Model for Augmented Reality Systems, International Journal of Advanced Trends in Computer Science and Engineering, Vol. 9. № 1, 2020, pp. 637-642. doi:10.30534/ijatcse/2020/89912020.

11 M. Iasechko, M. Kolmykov, V. Larin, S.Bazilo, H. Lyashenko, P. Kravchenko, N. Polianova and I. Sharapa. Criteria for performing breakthroughs in the holes of radio electronic means under the influence of electromagnetic radiation, ARPN Journal of Engineering and Applied Sciences, 15(12), 2020, pp. 1380 - 1384. 
12 O. Sotnikov, M. Iasechko, V. Larin, O. Ochkurenko, and D.Maksiuta. The model of a medium for creation of electric hermetic screens of the radio electronic means, IJATCSE. 8(2), 2019, pp. 300-304. doi:10.30534/IJATCSE/2019/32822019.

13 M. Iasechko, O. Tymochko, Y. Shapran, I. Trofymenko, D. Maksiuta, and Y. Sytnyk. Loss definition of charged particles in the discharge gap of the opening of the box-screens during the formation of a highly conductive channel, IJATCSE. 8(1.3), 2019, pp. 1-9. doi: 10.30534/ijatcse/2019/0181.32019.

14 M. Iasechko, V. Larin, O. Ochkurenko, S. Salkutsan, L. Mikhailova, and O. Kozak. Formalized Model Descriptions Of Modified Solid-State Plasma-Like Materials To Protect Radio-Electronic Means From The Effects Of Electromagnetic Radiation, IJATCSE. 8(3), 2019, pp. 393-398. doi: 10.30534/ijatcse/2019/09832019.

15 M. Iasechko, V. Larin, O. Ochkurenko, A. Trystan, T.Voichenko, A. Trofymenko, and O. Sharabaiko. Determining the function of splitting the charged particles of the strongly ionized air environment in the openings of the case-screens of radioelectronic means, IJATCSE. 8(1.3), 2019, pp. 19-23. doi: 10.30534/ijatcse/2019/0481.32019.

16 M.M. Iasechko, and O.M. Sotnikov. Protecting of radio electronic facilities is from influence of powerful electromagnetic radiation, Published by Izdevnieciba Baltija Publishing, Collective monograph, Riga, 2019, pp.283-299.

17 A. Syrotenko, O. Sotnikov M. Iasechko, V. Larin, S.Iasechko O. Ochkurenko, and A. Volkov. Model of Combined Solid Plasma Material for the Protection of Radio-Electronic Means of Optical and Radio Radiation, IJATCSE, 8(4), 2019, pp. 1241 - 1247. doi:10.30534/ijatcse/2019/33842019.

18 O. Turinskyi, M. Burdin, M. Iasechko, V. Larin, Y. Gnusov, D. Ikaev, V. Borysenko, and V. Manoylo. Protection of board radioelectronic equipment from the destructive powerful electromagnetic radiation with the use of natural technologies, IJETER, 7(11), 2019, pp. 542 - 548. doi: 10.30534/ijeter/2019/237112019.

19 M. Iasechko, V. Larin, D. Maksiuta, O. Ochkurenko, I. Krasnoshapka, Y.Samsonov, H. Lyashenko, A.Zinchenko, and R.Vozniak. Model description of the modified solid state plasma material for electromagnetic radiation protection, IJETER, 7(10), 2019, pp. 376 - 382. doi: 10.30534/ijeter/2019/027102019.

20 O. Turinskyi, M. Iasechko, V. Larin, D. Dulenko, V. Kravchenko, O. Golubenko, D.Sorokin, and O. Zolotukhin. Model and development of plasma technology for the protection ofradio-electronic means of laser emission, IJATCSE. 8(5), 2019, pp. 2429-2433. doi:10.30534/IJATCSE/2019/85852019.

21 M.Iasechko, Y. Gnusov, I. Manzhai, O. Uhrovetskyi, V.Manoylo, A. Iesipov,O. Zaitsev, M. Volk, and O. Vovk. Determination of requirements for the protection of radio-electronic equipment from the terroristic influence by electromagnetic radiation, IJETER, 7(12), 2019, pp. $772-777$. doi: 10.30534/ijeter/2019/077122019.

22. H. Khudov, R. Khudov, I. Khizhnyak, V. Loza, T. Kravets, S. Kibitkin Estimation of the Kullback-Leibler Divergence for Canny Edge Detector of Optoelectronic Images Segmentation, International Journal of Emerging Trends in Engineering Research, Vol. 8. № 7, 2020, pp. 3927-3934. DOI: doi:10.30534/ijeter/2020/162872020. 